\title{
The Effect of Wood Condition on Sound Wave Propagation
}

\author{
Ahmed El-Hadad1, Graham Ian Brodie², Berhan Shiday Ahmed1 \\ ${ }^{1}$ Department of Forest and Ecosystem, Faculty of Science, The University of Melbourne, Melbourne, Australia \\ ${ }^{2}$ Department of Agriculture and Food Science, Faculty of Veterinary and Agricultural Sciences, The University of Melbourne, \\ Melbourne, Australia \\ Email: ael_hadad@hotmail.com
}

How to cite this paper: El-Hadad, A., Brodie, G.I. and Ahmed, B.S. (2018) The Effect of Wood Condition on Sound Wave Propagation. Open Journal of Acoustics, 8, 37-51.

https://doi.org/10.4236/oja.2018.83004

Received: May 22, 2018

Accepted: August 17, 2018

Published: August 20, 2018

Copyright (c) 2018 by authors and Scientific Research Publishing Inc. This work is licensed under the Creative Commons Attribution International License (CC BY 4.0).

http://creativecommons.org/licenses/by/4.0/

\begin{abstract}
This experiment aims to study the effects and modifications that occurred on acoustic signal harmonics when travelling through wood. The experiment measured the output amplitudes and frequencies of the travelling signals and compared them with the original input signal. The factors under investigation in this experiment included: wood type, wood moisture content (MC), input signal frequencies, signal travelling distance and wood condition (wood with/without cracks). The experiment findings demonstrated that higher input signal frequencies results in higher attenuation of acoustic emissions (AE) travelling through the wood. The results also indicate that: wood type, MC, the signal's travelling distance, and the orientation of the travelling signal, compared to the wood's grain direction, affected the signal propagation.
\end{abstract}

\section{Keywords}

Acoustic Emission, Sound Wood Interaction, Moisture Content, Sound Wave Propagation, Wood Condition

\section{Introduction}

Wood or timber is dead organic material derived from living trees. The majority of houses in Australia are partly constructed with timber framing. The roof construction, door, floor, architraves, skirting boards, window frames and wardrobes are usually made of timber. Natural wood is composed of cellulose (40\% $44 \%)$, lignin $(16 \%-33 \%)$, hemicelluloses $(27 \%-44 \%)$ and a slight amount of extraneous materials $(5 \%-20 \%)$ which are mostly organic extractives such as tannins [1] [2]. Wood is divided into two main categories: hardwood which are timber converted from flowering trees (Angiospermae subdivision) and soft- 
wood which are timber converted from the Gymnosperms (Gymnospermae subdivision) [1] [3]. The names softwood and hardwood may give a wrong impression of their texture or weight. Softwood is generally, but not necessarily, a light density type of wood. Likewise, hardwoods are generally, but not necessarily, high density and hard types of wood [4]. Hardwoods are more widely distributed than softwoods [3]. Hardwoods have traditionally been used for joinery and floors which undergo heavy wear and tear [1]. Hardwood and softwood differ, not only in their external appearance, but also in their anatomical structure and/or morphology. The types of cells, their relative numbers and their arrangement are all different [3].

Wood is susceptible to their ambient moisture. Wood moisture affects wood properties and structure. Different wood structural components are hygroscopic. There are several levels at which hygroscopicity operates: the molecular level, where water bonds to sites in the three main polymers that make up woody materials; the micro-structural level, in which voids in the cellular structure with small openings (pits) effectively hold water in the cells; and the macro-structure of wood with conductive channels (called veins) in hardwood that channel water along the grain [5]. They attract water and make the wood structure rather hygroscopic which increases the density of wood [6]. Moisture in the wood creates a good condition for biological agents such as fungi to thrive [1]. Hence, wood drying becomes essential before the wood can be used in service [5]. Solar drying methods which have low energy consumption are cost effective and produce high-quality timber, but this is a much slower method than many other kiln systems [5] [7].

Acoustic Emission (AE) is the transient mechanical wave or elastic energy naturally released by materials undergoing deformation and generated by abrupt localised changes of strain within a body. This energy travels in the material as a strain or stress wave and can be identified using a piezoelectric transducer which translates the surface movements to an electrical signal [8] [9] [10] [11]. AE can be produced as a result of dislocation motion and crack growth in materials. Any tiny plastic deformation can result in elastic waves which may cause external vibration of a body. If the surface motion's amplitude is enough, it can be detected by $\mathrm{AE}$ sensors or transducers attached to the vibrated surface [9] [10]. AE sensors convert a material's mechanical vibration into a voltage-time waveform. Various information of the source, such as location and characteristics, can be retrieved by analysing the captured signal from AE sensors [9] [12]. Since the 1970s, Acoustic Emission has been widely used as a passive non-destructive testing technique [13].

Using $\mathrm{AE}$ as a monitoring technique is a very promising non-destructive method of detecting cracking strength in wooden substances exposed to differences in Relative Humidity (RH) and temperature [14] [15]. The wavelet transform of the ultrasound signals into the frequency components made it possible to identify AE events related to damage [14]. However, Kloiber, et al. [16] suggested that using $\mathrm{AE}$ is not always sufficient or reliable to detect wood defects 
and needs to be supported by traditional visual inspection. Dündar, et al. [17] examined the acoustic method as a quick and non-destructive technique to forecast dimensional stability of two types of hardwood, namely sweet chestnut (Castaneasativa) and sessile oak (Quercuspetraea). Wood samples were set under the fibre saturation point (FSP). Dündar, et al. [17], Dündar, et al. [18] presented that the wave velocity in the woods decreased as MC increased. Using specific gravity alone was a poor predictor of wood shrinkage, while using ultrasonic velocity alone was a good predictor. However, the best results for prediction of shrinkages of oak and chestnut were obtained when both ultrasonic velocity and specific gravity methods were combined [17].

Wood interacts with sound in different ways. It can absorb, produce and amplify sound signals. This type of interaction makes wood one of the leading materials to be used in musical instruments [19]. Wood is not only well known for its acoustic quality in various musical instruments but also considered a sound absorber or sound diffuser [20] [21]. Wood's vibrational properties depend on the properties of that species of wood, the vibrator's size and shape and the direction of nodal lines relative to grain structure [22].

Acoustic Emission (AE) is produced due to stress that is applied to a material. It can be identified with a piezoelectric transducer that is physically attached to the surface of the measured material. Kasal, et al. [23] applied stress waves in longitudinal and transverse directions and studied the correlation between measured physical parameters (e.g. time of flight (TOF), frequencies and velocity) and material properties (e.g. strength properties and elasticity). Kasal, et al. [23] found that there is a relatively strong correlation between static and dynamic modulus of elasticity. However, dynamic modulus of elasticity showed poor correlation with other mechanical properties. Acoustic wave behaviour changes as medium properties change. Lately, wave propagation change, as a function of moisture content (MC), was explored by several researchers, aiming to use it for assessing and monitoring MC levels of the wood [24]. Modulus of elasticity, wave speed, attenuation and creep characteristics are just a few of the physical and mechanical properties of wood affected by wood moisture content [24].

Several studies have explored the effect of moisture content (MC) on acoustic wave velocity. They concluded that increasing the MC level to fibre saturation point (FSP) causes the velocity of acoustic waves to decrease [25] [26] [27] [28]. With the presence of decay in the wood, ultrasonic wave attenuation increases and velocity decreases [25] [29]-[34]. The solid wood's grain direction affects wood acoustic impedance. When the acoustic signal is emitted along the grain in wood, the acoustic impedance is comparable to that of metals, whereas for across the grain acoustic signal it is similar to plastics and water [35] [36]. Most commercial transducers impedance is matched to metals or ceramics which does not match with the transverse surface of wood. Acoustic coupling is most often applied to the transverse surface of wood. That will cause a great difference between transducer impedance and wood when measuring sound waves across the 
grain [28] [35].

This experiment studied the modifications that occurred to acoustic signal harmonics when travelling through wood. A sound recording technique was used in this experiment. This experiment tested output amplitudes and frequencies of the travelling signals and compared them with the original input signal values.

\section{Method}

A microphone was coupled to the speaker that sent the input signal through the wood sample. This recorded input signal was used as a reference point/control and allowed comparison of its characteristics with the output signal once that had travelled through wood. The factors under investigation in this experiment included: wood type (softwood/hardwood), wood moisture content (MC) levels (Low (L), Normal (N) and High (H)), Signal Generator (SG) input signal frequency $(1,5,10,15,20,25,50$ and $100 \mathrm{kHz})$, signal travelling distance (0 for input signal (control), 200, 400, 600, 800 and $1000 \mathrm{~mm}$ ) and wood condition (wood with cracks $(\mathrm{C})$ and wood with no cracks $(\mathrm{N})$ ). The objective of this experiment was to study the changes that occurred to the sound waves travelling through different types of wood under various conditions. The factors addressed in this study included wood type. Two types of wood were used in this experiment, softwood and hardwood stakes (Radiata Pine D. Don) as a softwood and Blue Gum Eucalyptus globulus Ordinary Buildings (OBH) hardwood as a hardwood respectively. Wood moisture content (MC), signal travelling distance, signal travelling direction or orientation in the wood (along and across the grain) and input signal frequency were also included in this study. This experimental study tested the output amplitude and frequency of travelling signals and compared them with the original input signal values.

The equipment used in this experiment were: Softwood and hardwood stakes (Radiata Pine D. Don) as a softwood and Blue Gum Eucalyptus globulus Ordinary Buildings Hardwood (OBH) as a hardwood of different dimensions (four wood samples of softwood labelled as (L1, L2, L3 and L4) of dimensions $70 \times 70$ $\times 1000 \mathrm{~mm}$ and four wood samples of hardwood labelled as (L1, L2, L3 and L4) of dimensions $42 \times 100 \times 1000 \mathrm{~mm}$ ), oscillator/signal generator (EMONA, model LAB4, 4-in-1 instrument), laptop with audio recording application (Audacity, v2.0.1), and one standard microphone (U-602, $9.7 \mathrm{~mm}$ diameter and $6.7 \mathrm{~mm}$ height, $20 \mathrm{~Hz}-16 \mathrm{kHz}$ frequency range, and sensitivity of $68 \mathrm{~dB}$ ). The microphone was attached to a $4 \mathrm{~m}$ long coaxial cable. A standard speaker (AS-3000 $57 \mathrm{~mm}$ diameter, $0.25 \mathrm{~W}, 8 \Omega, 50 \mathrm{~Hz}-4 \mathrm{kHz}$ ) was used to generate the audio signals in the wood and sound absorption mat (AX-3660, $680 \times 330 \mathrm{~mm}$ ) was used to prevent unwanted reflections and interference from the environment in which the experiment was conducted.

As indicated in Figure 1, the signal generator sent a square wave signal through the wood sample along the grain using a standard speaker. A square 


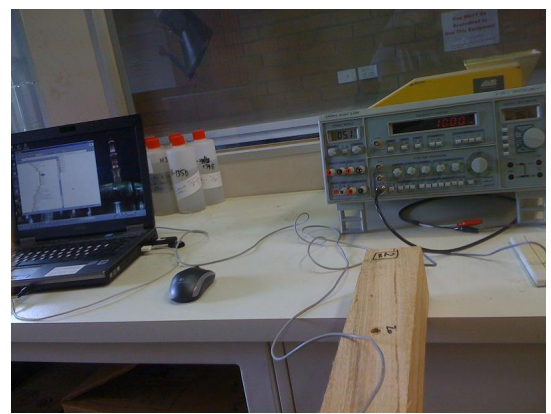

(a)

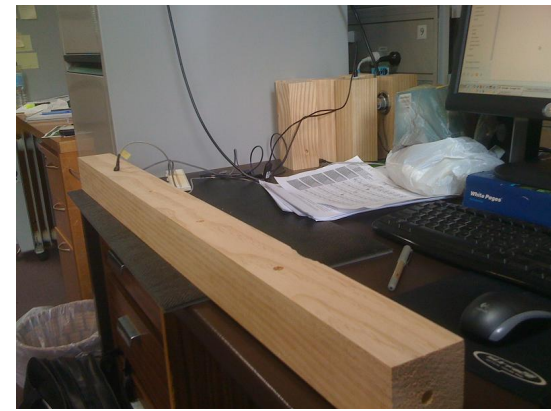

(b)

Figure 1. Sound experiment setup. (a) The oscillator is used to generate the square signal and send it through the speaker which is fitted on the wood cross-section; (b) The microphone is fitted in the wood stake to record the output signal that was sent by the speaker located in the far cross-section side.

wave was used, rather than a pure tone, because it generates multiple harmonics that allow a wide range of frequencies to be investigated simultaneously in the same measurement procedure; which is explained further in Section 1.1. The received signal was recorded by a standard microphone that was fixed in one of five holes, which were drilled into the wood sample at $200 \mathrm{~mm}$ spacing along the wood sample. Each hole was of $10 \mathrm{~mm}$ diameter and $10 \mathrm{~mm}$ deep. The holes were drilled in the wood to minimise background noises from interfering with the generated signal from the SG. A four-metre long coaxial cable was soldered to the standard microphone's three pins from one side and to TRS (Tip-Ring-Sleeve) $3.5 \mathrm{~mm}$ connector at the other end. The Tip and Ring were short-circuited in the cable at the TRS connector side to convert the three-pin microphone into a two-pin arrangement. These two pins sent the output signal to the audio card of the laptop which was running the Audacity application to record the audio signal.

A comparison between wood stake's input and output signals was performed by recording each of the output signals along the wood blocks through Audacity. At the first hole, which was at $0 \mathrm{~mm}$ distance, the microphone recorded the input signal information. This signal was used as the control signal. By moving the microphone to the following holes one after another, the microphone recorded the output signals at 200,400,600, 800 and $1000 \mathrm{~mm}$ away from the input signal. A sound absorption mat was placed under the wood block to reduce the sound that might be reflected from the surface of the work bench. To test the samples at different moisture content (MC), all wood samples were submerged in a deep water container for three days for maximum moisture absorption. When the samples were removed from water, MC was calculated to obtain the MC levels. Kettunen [6] considered that the moisture content of wood can be calculated based on two different definitions: 1) it is the ratio of the mass of water $m_{w}$ to the total mass of wood $m$. In that case the moisture or water content is $m_{w} / m$ or 2) it is the moisture ratio (moisture quotient) which is defined as the ratio of the water content of the wood $m_{w}$ to the dry mass of wood $m_{o}$. In that case it will be 
equal to $m_{w} / m_{o}$ (where the total mass of wood $m=m_{o}+m_{w}$ ). The latter definition is mostly used by wood scientists. Additionally, a moisture meter was used to check and confirm the previous calculations' results.

Before submerging the samples in water, the MC level was measured and considered as low (L). After leaving the wood samples in the water for three days, softwood reached a maximum MC of $80 \%$, while hardwood reached a maximum MC of 35\%. A test was conducted at these levels and MC was considered as High $(\mathrm{H})$. The samples were then left to dry. When MC reached an average value between maximum MC (H) and Low (L) which is MC level before submerging the samples in water, MC at that level $(22.2 \%$ in the case of softwood and $16 \%$ in the case of hardwood) was considered as Medium (M) and a test was conducted.

To examine the mentioned factors, the experiment was conducted in two stages.

Experiment stage-1 included three steps: In step-1, for a period of approximately 15 seconds, the output signal was recorded for each wood block/stake (L1 to L4), each wood type (SW and HW), each frequency $(1,5,10,15,20,25,50$ and $100 \mathrm{kHz}$ ) and each distance (0 (as input signal/control), 200, 400, 600, 800 and $1000 \mathrm{~mm}$ ) successively. In step-2, holes were drilled randomly through the wooden stakes L1 and L2 to simulate cracks in the wood. The steps were repeated for both the SW and HW samples, with L1 and L2 in these species being considered as wood samples with cracks. In step-3, MC level was checked for wooden stakes L3 and L4 and considered as low level (L). Wood stakes L3 and L4 were submerged fully in water for three days to absorb water and to get the highest possible MC level. The test steps were repeated for SW and HW and MC level was calculated and considered as High $(\mathrm{H})$. Wood stakes L3 and L4 were allowed to dry until they reached an average MC level (which is between $\mathrm{L}$ and $\mathrm{H}$ levels). The test steps were repeated again and $\mathrm{MC}$ level was considered as Medium (M). Using audio recording application (Audacity), the output signals were recorded and analysed using Analyze, Plot Spectrum option. The wave spectrum details, Frequency $(\mathrm{Hz})$ and Level $(\mathrm{dB})$, were exported for further analysis.

Experiment stage- 2 is a subsequent step of stage- 1 results. The same experiment was conducted again but in three lower frequency levels which are less than $2.0 \mathrm{kHz}$ and a signal travelling distance less than $250 \mathrm{~mm}$. In this experiment, eight wood stake samples with dimensions of $(90 \times 45 \times 270 \mathrm{~mm})$ from each of SW and HW were used and labelled as (L1 to L8), three levels of MC were tested (L, $M$ and $H)$, for input signal frequencies of $(0.5,1.0$ and $2.0 \mathrm{kHz})$ and signal travelling distances of $(0,50,100,150,200$ and $250 \mathrm{~mm})$.

\section{Fourier Transform}

The Fourier series of the function: $f=f(t)$ with the period $=2 L$, can be expressed in the following form:

$$
S f(t)=a_{0}+\sum_{n=1}^{\infty}\left(a_{n} \cos \frac{n \pi t}{L}+b_{n} \sin \frac{n \pi t}{L}\right)
$$


where: $a_{0}=\frac{1}{2 L} \int_{-L}^{+L} f(t) \mathrm{d} t, \quad a_{n}=\frac{1}{L} \int_{-L}^{+L} f(t) \cos \frac{n \pi t}{L} \mathrm{~d} t$ and $b_{n}=\frac{1}{L} \int_{-L}^{+L} f(t) \sin \frac{n \pi t}{L} \mathrm{~d} t$.

Assuming a square wave of $L=\pi$ and $f(t)=\left\{\begin{array}{ll}1, & \text { for } 0<t<\pi \\ -1, & \text { for }-\pi<t<0\end{array}\right.$.

The square wave function has anti-symmetry or odd symmetry. As $a_{0}$ is an integration of $f(t)$ from $-L$ to $+L$, that will result in $a_{0}$ being 0 .

As $f(t)$ has odd symmetry and $\cos \frac{n \pi t}{L}$ has even symmetry, then multiplication of $f(t)$ and $\cos \frac{n \pi t}{L}$ has odd symmetry too. That results in $a_{n}$ terms being 0 as well.

Then $b_{n}$ values can be calculated as follows:

$$
\begin{aligned}
b_{n} & =\frac{1}{\pi} \int_{-\pi}^{+\pi} f(t) \sin n t \mathrm{~d} t=\frac{1}{\pi} \int_{-\pi}^{0}(-1) \sin n t \mathrm{~d} t+\frac{1}{\pi} \int_{0}^{\pi}(+1) \sin n t \mathrm{~d} t \\
& =\left.\frac{1}{n \pi} \cos n t\right|_{-\pi} ^{0}-\left.\frac{1}{n \pi} \cos n t\right|_{0} ^{\pi}=\frac{1}{n \pi} *(2)-\frac{1}{n \pi} *(-2)=\frac{4}{n \pi}
\end{aligned}
$$

with $a_{0}=0, a_{n}=0$ and $b_{n}=\frac{4}{n \pi}$, that will lead to the complete Fourier expression of this function as: $S f(t)=\frac{4}{\pi} \sum_{n=1}^{\infty} \frac{\sin n t}{n}$.

When $n$ is even value $(0,2,4$ and so forth), $\sin n t=0$ and $S f(t)=0$.

So, the final expression ends up with: when $n$ is an odd value,

$$
(t)=\frac{4}{\pi} \sum_{n=1,3,5, \cdots}^{\infty} \frac{\sin n t}{n}
$$

This result is useful to support the results analysis.

\section{Results}

As there were many factors to be considered in this experiment (e.g. wood type, input frequencies, output signal amplitude, signal travelling distance, crack on the wood and MC level), the data set is too large to be presented within this paper. A sample of these test results will therefore be provided in the following section. For example, the following test was conducted on a sample of hardwood (HW) type, with cracks on it (C), using wood stake (L1), at different frequencies $(1,5,10,15,20,25,50$ and $100 \mathrm{kHz})$.

Table 1 shows the legend used in experiment stage- 1 .

From Figure 2, some important results can be demonstrated. Results confirm Fourier transform calculations of square wave, which led to eliminating the values of $a_{0}$ and $a_{n}$, where $b_{n}$ is the only value left. Frequencies that are above $20 \mathrm{kHz}$ cannot be detected. This result is expected due to the frequency range supported by both the microphone and speaker that were used in this experiment $(20 \mathrm{~Hz}-16 \mathrm{kHz}$, sensitivity $68 \mathrm{~dB}$ ). Having a close look at the frequency 


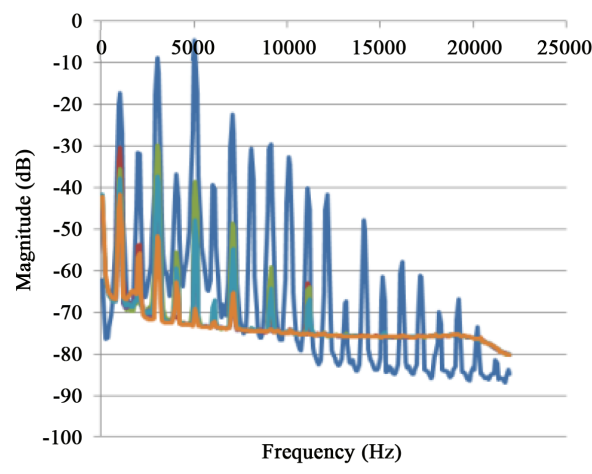

(a)

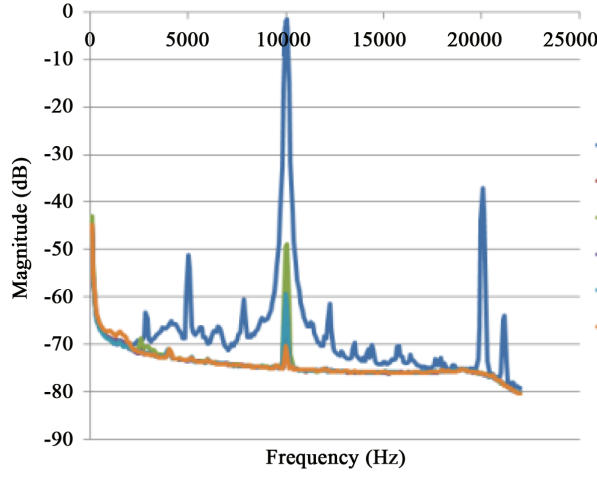

(c)

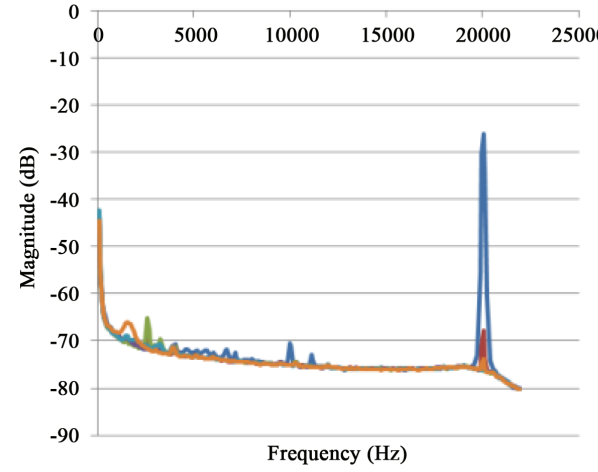

(e)

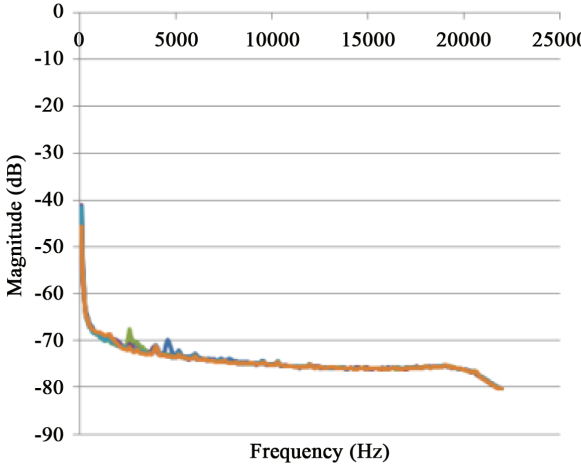

(g)

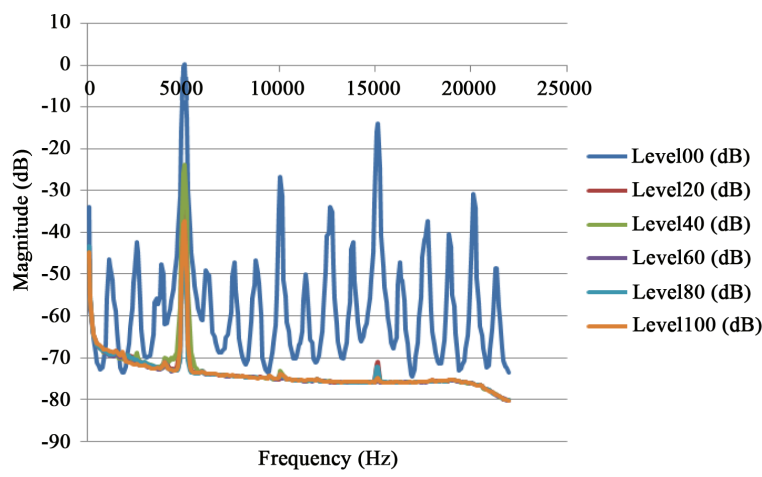

(b)

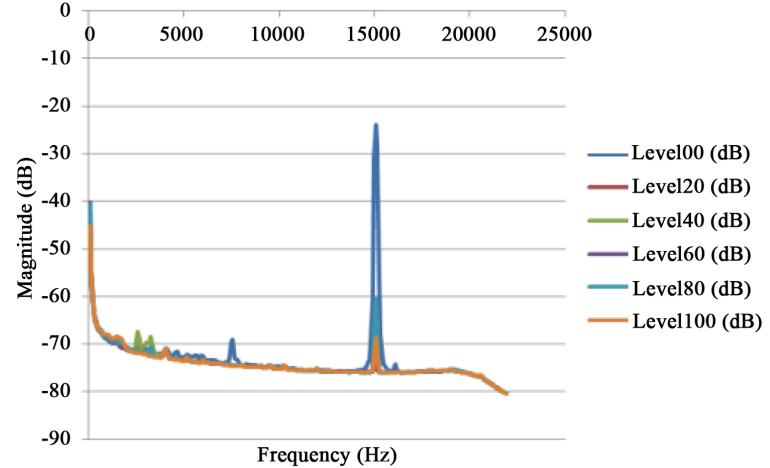

(d)

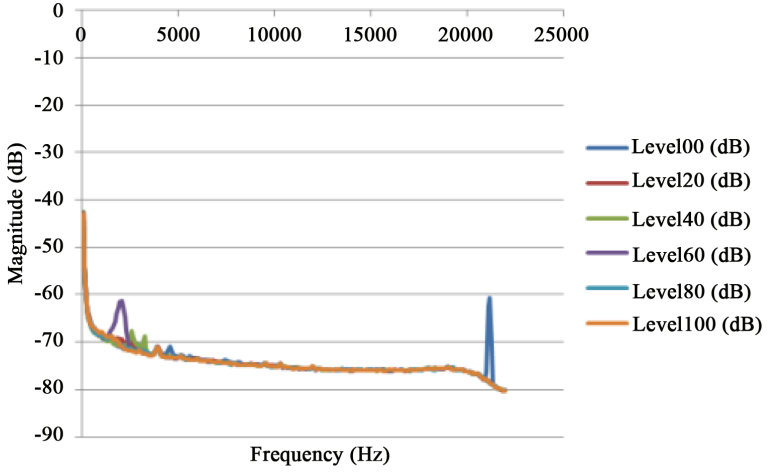

(f)

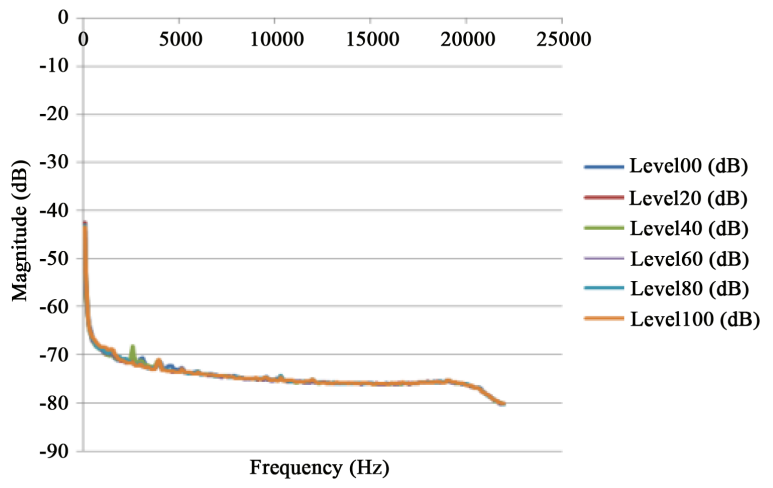

(h)

Figure 2. Experiment stage-1 test results. (a) HW-C-L1-1 kH; (b) HW-C-L1-5 kH; (c) HW-C-L1-10 kH; (d) HW-C-L1-15 kH; (e) HW-C-L1-20 kH; (f) HW-C-L1-25 kH; (g) HW-C-L1-50 kH; (h) HW-C-L1-100 kH. 
Table 1. The legend used in experiment stage-1.

\begin{tabular}{cc}
\hline Code & Description \\
\hline SW & Softwood sample \\
HW & Hardwood sample \\
Level $\mathrm{xxx}(\mathrm{dB})$ & $\begin{array}{r}\text { Output signal amplitude in dB when measured at } \\
\text { xxx (cm) distance from input signal }\end{array}$ \\
Lx & Sample log number x (Four Logs were labelled as L1 to L4) \\
C & Sample wood with cracks \\
$\mathrm{N}$ & Sample wood in normal condition (i.e. No cracks for logs L1 \& L2) \\
$\mathrm{H}$ & High MC level \\
$\mathrm{M}$ & Medium MC level \\
$\mathrm{L}$ & Low MC level \\
$\mathrm{Xx} \mathrm{kHz}$ & Input signal frequency in xx kHz (1, 5, 10, 15, 20, 25, 50 and 100 kHz) \\
\hline
\end{tabular}

responses in Figure 2, the highest output signal responses were in the lower frequencies (that less than $2.0 \mathrm{kHz}$ ) while the responses almost vanished at higher frequencies. The output signal vanishes for more than $250 \mathrm{~mm}$ travelling distance.

The Matlab ${ }^{\varpi}$ application was used to calculate Multi-Factor Analysis of Variance (ANOVA) for fixed input frequencies 1.0 and $5.0 \mathrm{kHz}$ successively. It is important to note here that two replicates were removed from each of the "Normal" samples to have the same number of samples, in order to balance the data for this analysis. Also, the $0 \mathrm{~mm}$ distance data (i.e. the input signal) was removed in this analysis.

As illustrated in Table 2, ANOVA revealed that frequency, wood condition and distance individually had a significant effect on the acoustic signal traveling through the wood samples. There was also significant interaction between: Frequency and Wood Type; Frequency and Wood Condition; Wood Condition and Distance; and Frequency, Wood Type and Wood Condition as shown in Table 2.

Table 2 is the outcomes of a multi-factor Analysis of Variance (ANOVA), which is a standard statistical tool, used to determine the level of influence that different treatments and treatment combinations have had over the experimental results. In accordance with all standard statistical analyses, ANOVA tests the probability of the null hypothesis, which is that each treatment or treatment combination has had no effect on the experimental outcomes being true. If this probability drops below an accepted level, such as 0.05 , the treatment or treatment combination is determined to have a significant influence over the experimental data and are deemed to be causal in nature. The individual treatments or treatments that significantly influence the experimental outcomes are highlighted by an asterisk $\left.{ }^{*}\right)$ in the far-right column of the table. Therefore, at an 
Table 2. Multi-factor Analysis of Variance (ANOVA) for acoustic response as a function of: frequency, wood type, wood condition, and distance from source.

\begin{tabular}{|c|c|c|c|c|c|}
\hline Source & Sum Sq. & d.f. & Mean Sq. & $\mathrm{F}$ & Prob $>$ F \\
\hline Frequency & 208,950 & 6 & 34824.99371 & 1883.95303 & $5.58 \mathrm{E}-263^{*}$ \\
\hline Wood Type & 50.67471 & 1 & 50.67470551 & 2.741386424 & 0.098676171 \\
\hline Wood Condition & 1048.802 & 4 & 262.2005748 & 14.18445532 & $9.70 \mathrm{E}-11^{*}$ \\
\hline Distance & 284.3157 & 4 & 71.07891355 & 3.845207717 & $0.004507683^{*}$ \\
\hline Frequency $\times$ Wood Type & 845.0041 & 6 & 140.8340143 & 7.618800167 & $1.06 \mathrm{E}-07^{*}$ \\
\hline Frequency $\times$ Wood Condition & 925.9689 & 24 & 38.58203614 & 2.087200488 & $0.002341239^{*}$ \\
\hline Frequency $\times$ Distance & 342.5408 & 24 & 14.2725325 & 0.772111578 & 0.772020472 \\
\hline Wood Type $\times$ Wood Condition & 103.7109 & 4 & 25.92772653 & 1.402631092 & 0.232624518 \\
\hline Wood Type $\times$ Distance & 51.23743 & 4 & 12.80935692 & 0.692957104 & 0.597233393 \\
\hline Wood Condition $\times$ Distance & 570.894 & 16 & 35.68087216 & 1.930254109 & $0.017081393^{*}$ \\
\hline $\begin{array}{c}\text { Frequency } \times \text { Wood Type } \times \\
\text { Wood Condition }\end{array}$ & 2287.105 & 24 & 95.29603078 & 5.155298732 & $7.87 \mathrm{E}-13^{*}$ \\
\hline Frequency $\times$ Wood Type $\times$ Distance & 327.3671 & 24 & 13.64029775 & 0.737909114 & 0.81194616 \\
\hline Frequency $\times$ Wood Condition $\times$ Distance & 1302.834 & 96 & 13.57118877 & 0.734170476 & 0.964604773 \\
\hline $\begin{array}{c}\text { Wood Type } \times \\
\text { Wood Condition } \times \text { Distance }\end{array}$ & 491.6478 & 16 & 30.72798604 & 1.662314224 & 0.052058394 \\
\hline $\begin{array}{c}\text { Frequency } \times \text { Wood Type } \times \\
\text { Wood Condition } \times \text { Distance }\end{array}$ & 1572.715 & 96 & 16.38244298 & 0.886252941 & 0.758230381 \\
\hline Error & 6469.773 & 350 & 18.48506473 & & \\
\hline Total & $225,624.6$ & 699 & & & \\
\hline
\end{tabular}

*Indicates treatment combinations with statistically significant differences.

individual treatment level: frequency of the acoustic signal; the wood condition (i.e. the level of moisture ( $\mathrm{L}, \mathrm{M}$, or $\mathrm{H}$ ) and whether the wood is normal or cracked ( $\mathrm{N}$ or $\mathrm{C})$ ); and Distance from the source all significantly affected the propagation of sound in wood during this experiment. Additionally, various combinations of frequency, wood type (i.e. SW or HW), wood condition, and distance from the source have also significantly affected the propagation of sound during this experiment. In short, all the experimental parameters have had some causal effect on the propagation of sound in the wood during this experiment. These effects will be explained further through the remainder of this paper.

From Table 3, increasing frequency, moisture content, and distance from the signal source significantly reduced acoustic signal transmission; however, there appeared to be no significant effects due to wood type (SW or HW). Signals above $5 \mathrm{kHz}$ were significantly attenuated and probably fell below the dynamic range of detection for the experimental system; therefore, other factors had not significant on these higher frequencies (Table 3). 
A. El-Hadad et al.

Table 3. Acoustic signal strength $(\mathrm{dB})$ as a function of: wood type, wood condition; distance from source; and frequency.

\begin{tabular}{|c|c|c|c|c|c|c|c|c|c|}
\hline \multirow{2}{*}{ Wood Type } & \multirow{2}{*}{ Condition } & \multirow{2}{*}{$\begin{array}{c}\text { Distance } \\
(\mathrm{mm})\end{array}$} & \multicolumn{7}{|c|}{ Frequency $(\mathrm{kHz})$} \\
\hline & & & 1 & 3 & 5 & 7 & 9 & 11 & 13 \\
\hline \multirow{25}{*}{ Softwood } & \multirow{5}{*}{$\mathrm{N}$} & 20 & -33.2 & -36.5 & -60.0 & -75.6 & -78.3 & -79.2 & -79.8 \\
\hline & & 40 & -34.4 & -36.2 & -56.9 & -75.1 & -78.3 & -79.4 & -79.8 \\
\hline & & 60 & -39.7 & -41.0 & -54.0 & -76.3 & -78.0 & -79.3 & -79.8 \\
\hline & & 80 & -43.4 & -36.4 & -64.2 & -77.4 & -78.5 & -79.3 & -79.9 \\
\hline & & 100 & -43.6 & -43.6 & -55.1 & -77.4 & -78.4 & -79.4 & -79.8 \\
\hline & \multirow{5}{*}{$\mathrm{C}$} & 20 & -32.5 & -35.0 & -60.1 & -73.7 & -72.8 & -75.3 & -75.8 \\
\hline & & 40 & -32.4 & -39.0 & -59.5 & -73.1 & -73.5 & -75.3 & -75.7 \\
\hline & & 60 & -29.5 & -33.5 & -59.7 & -73.5 & -74.8 & -75.8 & -76.3 \\
\hline & & 80 & -32.3 & -36.0 & -61.4 & -73.0 & -74.5 & -75.2 & -75.8 \\
\hline & & 100 & -35.6 & -49.3 & -60.2 & -73.4 & -74.4 & -75.2 & -75.7 \\
\hline & \multirow{5}{*}{$\mathrm{H}$} & 20 & -24.9 & -39.5 & -58.2 & -72.4 & -72.7 & -75.1 & -75.7 \\
\hline & & 40 & -34.1 & -41.6 & -60.0 & -73.6 & -74.6 & -75.3 & -75.9 \\
\hline & & 60 & -31.4 & -45.0 & -57.5 & -73.5 & -74.1 & -75.2 & -75.7 \\
\hline & & 80 & -30.9 & -41.1 & -64.1 & -73.4 & -74.4 & -75.3 & -75.6 \\
\hline & & 100 & -30.2 & -31.7 & -56.3 & -72.7 & -73.9 & -75.3 & -75.7 \\
\hline & \multirow{5}{*}{$\mathrm{L}$} & 20 & -18.8 & -40.6 & -52.0 & -73.7 & -74.8 & -75.7 & -76.0 \\
\hline & & 40 & -20.6 & -35.3 & -60.9 & -74.0 & -74.6 & -75.7 & -76.0 \\
\hline & & 60 & -20.0 & -36.3 & -53.5 & -74.0 & -74.1 & -75.6 & -76.0 \\
\hline & & 80 & -27.9 & -44.3 & -54.5 & -74.3 & -74.6 & -75.7 & -76.1 \\
\hline & & 100 & -30.7 & -35.8 & -61.5 & -73.9 & -74.9 & -75.6 & -75.9 \\
\hline & \multirow{5}{*}{ M } & 20 & -22.8 & -37.1 & -47.7 & -72.8 & -73.2 & -75.4 & -75.8 \\
\hline & & 40 & -26.5 & -47.3 & -49.5 & -73.6 & -73.7 & -75.3 & -75.9 \\
\hline & & 60 & -24.7 & -47.3 & -62.8 & -74.0 & -74.2 & -75.4 & -75.8 \\
\hline & & 80 & -27.4 & -41.4 & -53.7 & -73.9 & -74.8 & -75.4 & -75.8 \\
\hline & & 100 & -27.2 & -38.4 & -54.6 & -73.7 & -74.3 & -75.4 & -75.7 \\
\hline \multirow{10}{*}{ Hardwood } & \multirow{5}{*}{$\mathrm{N}$} & 20 & -29.5 & -43.5 & -65.4 & -73.2 & -74.5 & -75.3 & -75.7 \\
\hline & & 40 & -26.8 & -39.4 & -68.8 & -72.8 & -74.4 & -75.1 & -75.6 \\
\hline & & 60 & -29.6 & -40.7 & -65.4 & -73.7 & -74.6 & -75.2 & -75.7 \\
\hline & & 80 & -28.4 & -35.7 & -66.9 & -73.1 & -74.5 & -75.3 & -75.6 \\
\hline & & 100 & -34.5 & -53.1 & -69.6 & -73.6 & -74.5 & -75.3 & -75.8 \\
\hline & \multirow{5}{*}{$\mathrm{C}$} & 20 & -29.6 & -38.9 & -51.0 & -67.6 & -71.0 & -74.0 & -75.8 \\
\hline & & 40 & -37.1 & -37.2 & -47.5 & -64.5 & -68.3 & -74.8 & -75.9 \\
\hline & & 60 & -49.4 & -38.8 & -56.2 & -69.8 & -74.2 & -75.5 & -75.8 \\
\hline & & 80 & -45.1 & -34.6 & -53.0 & -69.9 & -70.1 & -75.2 & -75.9 \\
\hline & & 100 & -36.3 & -40.0 & -62.8 & -71.1 & -74.3 & -75.4 & -75.9 \\
\hline
\end{tabular}




\begin{tabular}{|c|c|c|c|c|c|c|c|c|}
\hline & 20 & -27.7 & -33.6 & -55.7 & -71.0 & -73.6 & -75.4 & -75.8 \\
\hline & 40 & -34.7 & -44.1 & -63.6 & -72.4 & -74.5 & -75.3 & -75.8 \\
\hline $\mathrm{H}$ & 60 & -35.3 & -32.5 & -58.5 & -70.5 & -74.5 & -75.5 & -75.8 \\
\hline & 80 & -34.3 & -35.0 & -56.2 & -71.1 & -74.4 & -75.5 & -75.8 \\
\hline & 100 & -27.1 & -33.7 & -53.8 & -73.6 & -74.2 & -75.4 & -75.9 \\
\hline & 20 & -29.8 & -29.7 & -52.8 & -66.3 & -73.3 & -75.5 & -75.8 \\
\hline & 40 & -40.9 & -40.0 & -57.7 & -72.1 & -73.8 & -75.7 & -76.0 \\
\hline $\mathrm{L}$ & 60 & -36.5 & -43.3 & -58.4 & -69.1 & -73.7 & -75.3 & -75.7 \\
\hline & 80 & -35.5 & -40.1 & -61.9 & -67.0 & -72.5 & -75.3 & -75.8 \\
\hline & 100 & -27.2 & -32.6 & -50.3 & -68.8 & -72.6 & -75.4 & -76.0 \\
\hline & 20 & -33.3 & -37.4 & -60.5 & -65.0 & -74.1 & -75.4 & -75.9 \\
\hline & 40 & -33.2 & -37.6 & -62.8 & -69.3 & -74.3 & -75.4 & -75.8 \\
\hline $\mathrm{M}$ & 60 & -34.7 & -37.3 & -56.6 & -67.7 & -74.8 & -75.5 & -75.7 \\
\hline & 80 & -35.1 & -44.2 & -60.6 & -69.0 & -72.9 & -75.5 & -75.8 \\
\hline & 100 & -26.5 & -34.5 & -59.3 & -66.6 & -73.7 & -75.5 & -75.8 \\
\hline & \multicolumn{3}{|c|}{$\operatorname{LSD}(p=0.05)$} & & & & & 8.5 \\
\hline
\end{tabular}

\section{Discussion}

The aforementioned results revealed different factors that affect the audio signals travelling through the wood. Those factors were wood type, MC level and the travelling distance of the signal through the wood. In this experiment, higher input signal frequency resulted in higher attenuation of AE travelling signal in the wood. The results of "Table Type" in Table 2 also showed that there was no difference between softwood and hardwood. It is suggested that there must be some differences in sound coupling into hardwood and softwood. This could be due to the difference in their surface penetrability and roughness, which may decrease the connection area and cause penetration of the couplant into timber [35].

The results of this experiment also indicate that there are different factors that might affect the travelling AE signals through the wood. These factors are mainly: wood type, MC level, the signal's travelling distance and the orientation of the travelling signal, compared to the wood's grain. These results match those of other studies such as Senalik, et al. [24], Senalik, et al. [37] and Beall [35].

In the case of softwood the signal can travel further along the grain when compared to hardwood. However, some contradicting results were obtained by Reiterer, et al. [38] and Zombori [39], which revealed that, when travelling across the grain, AE signals could be detected more easily in the case of hardwood than in softwood, as it covers more spectra frequencies, due to the difference in hardwood structure. 


\section{Conclusion}

This paper covered the study of sound-wood interaction. It was observed that higher signal frequency resulted in higher attenuation of AE travelling signal in the wood. In addition, it was concluded that in the frequency range that was less than $5 \mathrm{kHz}$, the different wood conditions had little effect on the acoustic signal detection. The results also show that the higher the MC level in the wood, the higher the chance of detecting the AE travelling signal. AE signals that travelled across the grain could travel further and could be detected more easily compared to along the grain signals.

\section{Acknowledgements}

This work was supported by Australian Research Council, Linkage Project [grant number: LP0776778].

\section{Conflicts of Interest}

The authors declare no conflicts of interest regarding the publication of this paper.

\section{References}

[1] Ahmed, B.M., French, J.R.J. and Thorpe, J. (2005) Remedial Treatment of Timber-in-Service. In: VIC, Ed., Study Guide, CRC Wood Innovations, Melbourne, 201.

[2] Panshin, A.J. and Zeeuw, C.D. (1980) Textbook of Wood Technology: Structure, Identification, Uses, and Properties of the Commercial Woods of the United States and Canada. Vol. 1, Graw-Hill Education, New York.

[3] Shmulsky, R. and Jones, P.D. (2011) Forest Products and Wood Science. John Wiley \& Sons, Hoboken. https://doi.org/10.1002/9780470960035

[4] Wiedenhoeft, A.C. and Miller, R.B. (2005) Structure and Function of Wood. CRC Press, Boca Raton.

[5] Brodie, G. (2007) Microwave Treatment Accelerates Solar Timber Drying. American Society of Agricultural and Biological Engineers.

[6] Kettunen, P.O. (2006) Wood Structure and Properties. Trans Tech Publications Ltd., Stäfa.

[7] Brodie, G. (2004) Microwaves Speed up Solar Wood Drying. Resource: Engineering \& Technology for a Sustainable World, 11, 9.

[8] de la Rosa, J.J.G. (2005) An Application of the Independent Component Analysis to Monitor Acoustic Emission Signals Generated by Termite Activity in Wood. Measurement, 37, 63-76. https://doi.org/10.1016/j.measurement.2004.08.002

[9] Eitzen, D. and Wadley, H. (1984) Acoustic Emission: Establishing the Fundamentals. Journal of Research of the National Bureau of Standards, 89, 75-100. https://doi.org/10.6028/jres.089.008

[10] Grosse, C.U. and Ohtsu, M. (2008) Acoustic Emission Testing. Springer, Berlin. https://doi.org/10.1007/978-3-540-69972-9

[11] Kanji, O. (2012) Acoustic Emission. In: McGraw-Hill Encyclopedia of Science \& Technology, McGraw-Hill Education, New York.

[12] Landis, E.N. (2008) Acoustic Emissions in Wood. In: Grosse, C. and Ohtsu, M., 
Eds., Acoustic Emission Testing, Springer, Berlin, Heidelberg, 311-322. https://doi.org/10.1007/978-3-540-69972-9_12

[13] Keprt, J. and Benes, P. (2009) The Determination of Uncertainty in the Calibration of Acoustic Emission Sensors. International Journal of Microstructure and Materials Properties, 4, 85-103. https://doi.org/10.1504/IJMMP.2009.028435

[14] Jakieła, S., Bratasz, Ł. and Kozłowski, R. (2007) Acoustic Emission for Tracing the Evolution of Damage in Wooden Objects.

https://ezp.lib.unimelb.edu.au/login?url=https://search.ebscohost.com/login.aspx?di $\underline{\text { rect }=\text { true } \& \mathrm{db}=\text { edsjsr\&AN=edsjsr.20619490\&site }=\text { eds-live \&scope }=\text { site }}$

[15] Mankin, R. (2011) Perspective and Promise: A Century of Insect Acoustic Detection and Monitoring. American Entomologist, 57, 30-44.

[16] Kloiber, M., Reinprecht, L., Hrivnák, J. and Tippner, J. (2016) Comparative Evaluation of Acoustic Techniques for Detection of Damages in Historical Wood. Journal of Cultural Heritage, 20, 622-631. https://doi.org/10.1016/j.culher.2016.02.009

[17] Dündar, T., Wang, X., As, N. and Avci, E. (2013) Assessing the Dimensional Stability of Two Hardwood Species Grown in Turkey with Acoustic Measurements. Proceedings of the 18th International Nondestructive Testing and Evaluation of Wood Symposium, Madison, 24-27 September 2013, 459-468.

[18] Dündar, T., Wang, X., As, N. and Avci, E. (2016) Potential of Ultrasonic Pulse Velocity for Evaluating the Dimensional Stability of Oak and Chestnut Wood. Ultrasonics, 66, 86-90. https://doi.org/10.1016/j.ultras.2015.11.007

[19] Chopra, S. and Tsoumis, G.T. (2011) Wood-Acoustic Properties. http://www.britannica.com/EBchecked/topic/647253/wood/26165/Acoustic-propert ies

[20] Wassilieff, C. (1996) Sound Absorption of Wood-Based Materials. Applied Acoustics, 48, 339-356.

[21] Smardzewski, J. (2014) Experimental Study of Wood Acoustic Absorption Characteristics. Holzforschung, 68, 467. https://doi.org/10.1515/hf-2013-0160

[22] Sakurai, Y. and Skudrzyk, E.J. (1969) Acoustic Properties of Wood. The Journal of the Acoustical Society of America, 46, 124-124. https://doi.org/10.1121/1.1973434

[23] Kasal, B., Lear, G. and Tannert, T. (2011) Stress Waves. In: In Situ Assessment of Structural Timber, Springer, Berlin, 5-24.

[24] Senalik, C.A., Schueneman, G. and Ross, R.J. (2014) Ultrasonic-Based Nondestructive Evaluation Methods for Wood. USDA Forest Service, Forest Products Laboratory. https://doi.org/10.2737/FPL-GTR-235

[25] Gerhards, C.C. (1982) Longitudinal Stress Waves for Lumber Stress Grading: Factors Affecting Applications: State of the Art. Forest Products Journal, 32, 20-25.

[26] Sakai, H., Minamisawa, A. and Takagi, K. (1990) Effect of Moisture Content on Ultrasonic Velocity and Attenuation in Woods. Ultrasonics, 28, 382-385. https://doi.org/10.1016/0041-624X(90)90060-2

[27] Minamisawa, A. and Ozawa, A. (1994) Measurement of Moisture Diffusivity in Woods Using Ultrasounds. Journal of the Japan Wood Research Society (Japan), 40, 1052.

[28] Mishiro, A. (1996) Effect of Density on Ultrasonic Velocity in Wood. Mokuzai Gakkaishi, 42, 887-894.

[29] Wilcox, W.W. (1988) Detection of Early Stages of Wood Decay with Ultrasonic Pulse Velocity. Forest Products Journal, 38, 68-73.

[30] Pellerin, R.F., DeGroot, R.C. and Esenther, G.R. (1986) Nondestructive Stress Wave 
Measurements of Decay and Termite Attack in Experimental Wood Units. Proceedings of the 5th Nondestructive Testing of Wood Symposium, Pullman, 9-11 September 1986, 319-352.

[31] Patton-Mallory, M. and DeGroot, R.C. (1990) Detecting Brown-Rot Decay in Southern Yellow Pine by Acousto-Ultrasonics. 7 th International Symposium on Nondestructive Testing of Wood Symposium, Pullman, 29-44.

[32] Bauer, C., Kilbertus, G. and Bucur, V. (1991) Ultrasonic Technique for Determining the Extent of Fungus Attack of Beech and Pine Wood. Holzforschung.

[33] Lemaster, R.L. and Wilcox, W. (1993) The Use of Acousto-Ultrasonics to Detect Decay in Wood-Based Products. 2nd International Conference on Acousto-Ultrasonics, Atlanta, 188-190.

[34] Beall, F. (1994) Acoustic Emission from Oriented Strandboard during Flexural Testing. Proceedings of Progress in Acoustic Emission, Vol. 7, Sopporo, 148.

[35] Beall, F. (2002) Overview of the Use of Ultrasonic Technologies in Research on Wood Properties. Wood Science and Technology, 36, 197-212. https://doi.org/10.1007/s00226-002-0138-4

[36] Bucur, V. and Feeney, F. (1992) Attenuation of Ultrasound in Solid Wood. Ultrasonics, 30, 76-81. https://doi.org/10.1016/0041-624X(92)90037-M

[37] Senalik, C.A., Schueneman, G. and Ross, R.J. (2015) Ultrasonic-Based Nondestructive Evaluation Methods for Wood. Nondestructive Evaluation of Wood, 238, 21.

[38] Reiterer, A., Stanzl-Tschegg, S. and Tschegg, E. (2000) Mode I Fracture and Acoustic Emission of Softwood and Hardwood. Wood Science and Technology, 34, 417-430. https://doi.org/10.1007/s002260000056

[39] Zombori, B. (2001) In Situ Nondestructive Testing of Built in Wooden Members. NDT.net, Vol. 6, 212. 